\title{
Características citológicas del lavado bronqueoalveolar y respuesta inmune humoral frente a Aspergillus fumigatus en caballos Chilotes con obstrucción recurrente de las vías aéreas ${ }^{\#}$
}

\author{
Cytologic broncheoalveolar lavage findings and humoral immune response against \\ Aspergillus fumigatus in Chilote horses with recurrent airway obstructions "heaves"
}

\author{
G Morán ${ }^{\mathrm{a}, \mathrm{b} *}$, O Araya ${ }^{\mathrm{c}}$, A Ortloff ${ }^{\mathrm{d}}, \mathbf{H}$ Folch $^{\mathrm{a}}$ \\ ${ }^{a}$ Instituto de Inmunología, Facultad de Medicina, Universidad Austral de Chile, Valdivia, Chile. \\ ${ }^{\text {b} B e c a r i o}$ CONICYT, Programa de Doctorado en Ciencias Veterinarias, Universidad Austral de Chile, Valdivia, Chile. \\ ${ }^{\mathrm{c}}$ Instituto de Ciencias Clínicas Veterinarias, Facultad de Ciencias Veterinarias, Universidad Austral de Chile, Valdivia, Chile.

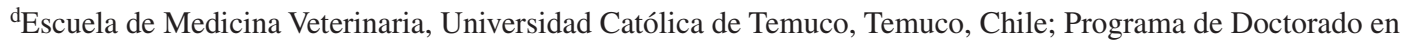 \\ Ciencias Veterinarias, Universidad Austral de Chile, Valdivia, Chile.
}

\begin{abstract}
SUMMARY
In this study, the presence and characteristics of the recurrent airway obstruction (RAO), in Chilote horses were investigated. The Chilote horse is a breed of small and very rustic horses, descendent from the horses that were brought by the spaniards during the colony and remained isolated in the Chiloe island, south of Chile, for a long time. Twenty two animals, all from the same farm and living under similar conditions, were physically examined. In all cases broncheoalveolar lavage (BALF) was performed and the recovered resident cells from the respiratory tract were studied in smears stained with May Grewald - Giemsa; the level of antibodies against Aspergillus fumigatus was determined by ELISA. The results indicate that out of the total population of animals under investigation, 13 showed clinical signs compatible with RAO and 9 were normal. In all cases, the animals that were considered RAO positive showed a higher percentage of polymorphonuclear neutrophils in the BALF: furthermore, a clear positive correlation between the relative amount of neutrophilic cells present in the airways and the severity of the signs observed during the physical examination exists. All of the animals, healthy and RAO positive horses, showed high titres of antibodies against A. fumigatus, a well known allergen, commonly distributed in the region and present in the hay/straw. Our results show that Chilote horses, even though they are a rustic bread, are very susceptible to become RAO positive with similar characteristics to those described in other breeds, moreover, all animals were sensitized to A. fumigatus antigens showing the immunogenicity and the important distribution of this fungal allergen.
\end{abstract}

Palabras clave: caballos Chilote, ORVA, LBA, alergia.

Key words: Chilote horses, RAO, BALF, allergy.

\section{INTRODUCCIÓN}

El caballo Chilote, mantenido en la Isla Grande de Chiloé desde la llegada de los españoles, es un recurso único en el mundo; antecedentes históricos, características morfológicas y su análisis genético confirman que tiene su origen en aquellos ejemplares equinos provenientes de la península ibérica durante el periodo de la conquista. En 1999 se aprobó formalmente la existencia de la raza del caballar Chilote y se abrieron los registros genealógicos, permitiendo la inscripción de los ejemplares que cumplen con los estándares establecidos. Una de las características de esta raza es su rusticidad y su capacidad de adecuarse al medio, lo que hace de estos animales una excelente herramienta para labores de tipo agrícola (Escobar y Tadich 2006). Estos equinos, a pesar de su rusticidad, al

Aceptado: 09.07.2008.

\# Financiado por proyecto DID-UACH 2006-04.

* Casilla 567, Valdivia, Chile; gmoran@uach.cl igual que las otras razas de caballos conocidas, desarrollan obstrucción recurrente de las vías aéreas (ORVA) si son expuestos a determinados alérgenos. El ORVA, conocido en inglés como RAO (recurrent airways obstruction), es consecuencia de un proceso inflamatorio originado por una hipersensibilidad gatillada por la inhalación de agentes alergénicos. Esta condición, debido a los mecanismos inmunológicos que intervienen en la patogénesis, tiene alguna similitud con el asma humana (Herszberg y col 2006, Morán y col 2006). Esta patología pulmonar equina se caracteriza por una inflamación de las vías aéreas, acumulación de mucus y obstrucción reversible, debido a la hipersensibilidad bronquial (Jackson y col 2000), lo que hace que el animal presente una gran disnea, caracterizada por doble espiración abdominal y tos seca. Si la patología lleva varios meses se puede apreciar la llamada línea del esfuerzo, la cual se debe a la hipertrofia de los músculos rectoabdominales. En los casos menos severos, sólo es posible observar una disminución en el rendimiento deportivo del caballo. 
La hipersensibilidad broncopulmonar de tipo I y la hipersensibilidad tipo III son los factores etiopatogénicos que se señalan como principales del ORVA (Robinson y col 2001, Horohov y col 2005); estos cuadros se desarrollan como consecuencia de una exagerada respuesta inmune humoral, que a su vez depende de la actividad de las células T CD4+ del tipo Th2 e IL-4 (Lavoie 2001). Adicionalmente, juegan un rol importante las citoquinas proinflamatorias que se producen como consecuencia de la entrada de los alérgenos en las vías respiratorias (Barnes y col 1998).

Entre los alérgenos más importantes como inductores de este cuadro alérgico están las esporas de Aspergillus fumigatus, hongo oportunista causante de varias patologías respiratorias tanto en hombre como en animales (Rementeria y col 2005). Las esporas de este hongo se encuentran principalmente en heno y paja almacenados con 20-30\% de humedad (Araya y Zaror 1995). También se han encontrado bacterias inductoras de hipersensibilidad pulmonar como Faenia rectivirgula y Thermoactinomices vulgaris, las que crecen en las mismas condiciones que el Aspergillus fumigatus (MacGorum y col 1998). Por otra parte, los ácaros del polvo son potencialmente alergénicos para humanos y caballos (Hockenjos y col 1981), y constituyen un factor de complicación, debido a que éstos se alimentan de esporas de hongos, las que son eliminadas como pellets fecales, los cuales también serían un factor para iniciar este cuadro alérgico en los equinos (Clarke y Madelin 1987).

El objetivo de este estudio es analizar las características citológicas del lavado bronqueoalveolar (LBA) de caballos Chilote con ORVA y compararlos con los resultados obtenidos de los animales sanos, determinar el grado de respuesta inmune humoral de estos animales contra Aspergillus fumigatus y determinar la importancia de este microorganismo en la inducción de este cuadro alérgico pulmonar en esta raza de caballos mantenidos en la Región de los Ríos de Chile.

\section{MATERIAL Y MÉTODOS}

\section{ANIMALES}

En el presente estudio se utilizaron 22 caballos Chilote. Los animales correspondieron a individuos de ambos sexos mantenidos estabulados durante la noche y alimentados con heno que, según pudo determinarse, contenía esporas de Aspergillus fumigatus. La contaminación por este hongo fue determinada usando el muestreador manual de Burkard como ha sido descrito anteriormente (Araya y Zaror 1995). El diagnóstico de ORVA se realizó mediante el examen clínico, lo cual permitió clasificar los animales según la intensidad de la signología clínica como ha sido propuesto por Robinson (2000). Además, los animales fueron sometidos a un lavado bronqueoalveolar (LBA) y a una inspección endoscópica del tracto respiratorio. Adicionalmente a los caballos incluidos en el experimento se les extrajo sangre por venopunción yugular para la realización de un hemograma y la obtención de suero, el que posteriormente fue congelado a $-20^{\circ} \mathrm{C}$ hasta su análisis.

\section{LAVADO BRONQUEOALVEOLAR}

Para la realización del LBA se ocupó una sonda Fogarty flexible de $180 \mathrm{~cm}$, la cual se introdujo vía nasotraqueal hasta un bronquio de tercera o cuarta generación. Para efectuar el examen, los caballos fueron sedados con Romifidina en dosis de $60 \mu \mathrm{g} / \mathrm{kg}$ vía endovenosa (Laboratorio Boehringer Ingelheim). El fin de este procedimiento fue facilitar la maniobra y evitar la tos paroxística al momento que la sonda traspasa la carina traqueal. Una solución fisiológica estéril a $37^{\circ} \mathrm{C}$ fue instilada en el árbol respiratorio mediante jeringas de $60 \mathrm{ml}$ en un volumen total de 180 $\mathrm{ml}$. Posteriormente se recuperó tanto líquido como fue posible. Luego las muestras fueron centrifugadas por 10 minutos a $2.500 \mathrm{~g}$ y seguidamente su componente celular fue sometido a conteo diferencial en frotis utilizando la tinción May-Grünwald Giemsa.

\section{PRUEBA DE ELISA PARA LA DETECCIÓN DE} INMUNOGLOBULINAS ESPECÍFICAS PARA LOS ANTÍGENOS DE ASPERGILLUS FUMIGATUS

Para detectar y cuantificar en los sueros problema la presencia de inmunoglobulinas específicas contra Aspergillus fumigatus se montó un ELISA indirecto. Para ello se utilizaron placas de microtitulación de 96 pocillos. A cada pocillo se le agregaron $100 \mu \mathrm{l}$ de antígeno de Aspergillus fumigatus en buffer carbonato $0,1 \mathrm{M}$ a pH 9,5, el cual se dejó incubando por 12 horas a $4{ }^{\circ} \mathrm{C}$. Posteriormente los pocillos de las placas se lavaron tres veces con $300 \mu \mathrm{lde}$ buffer PBS a pH 7,0 con 0,05\% de Tween 20. Luego los pocillos de la placa se bloquearon con $200 \mu \mathrm{l}$ de PBS con un $5 \%$ de leche descremada por una hora a $\mathrm{T}^{\circ}$ ambiente; la placa fue lavada tres veces con la solución de lavado. Terminado este proceso, se agregaron a cada pocillo 100 $\mu \mathrm{l}$ de suero de caballo diluido 1:100 en PBS, se incubó por una hora a $\mathrm{T}^{\mathrm{o}}$ ambiente, a continuación la placa fue lavada tres veces con la solución de lavado. Luego se agregaron a cada pocillo $100 \mu \mathrm{l}$ de suero antiinmunoglobulina de caballo preparado en conejo en una dilución 1:1000 e incubados por 1 hora a $37^{\circ} \mathrm{C}$; luego las placas fueron lavadas tres veces y cada pocillo fue cargado con $100 \mu \mathrm{l}$ de Ac antiIgG de conejo conjugado con peroxidasa diluido 1:1000. Posteriormente la placa fue lavada tres veces con solución de lavado para agregarle $100 \mu \mathrm{l}$ de solución de sustrato (buffer fosfato citrato a pH 5,0). La placa se incubó por 10 minutos a $\mathrm{T}^{\mathrm{o}}$ ambiente en oscuridad, luego la reacción colorimétrica se detuvo agregando $50 \mu \mathrm{l}$ de solución 2,5 M de ácido sulfúrico para colocarlo en el lector de ELISA con un filtro de $490 \mathrm{~nm}$. 


\section{OBTENCIÓN DE ANTÍGENOS DE ASPERGILLUS FUMIGATUS}

Para la obtención de las proteínas solubles de Aspergillus fumigatus usadas en el test de ELISA, el crecimiento del Aspergillus se dividió en dos partes: cultivo en agar peptona por 7 días a $23^{\circ} \mathrm{C}$ y luego cultivo en suspensión en caldo Malta por otros 7 días a $23^{\circ} \mathrm{C}$. La extracción de proteína se basó en el método descrito por Céspedes y col (1999). Para esto, los microorganismos se cosecharon por centrifugación y se fijaron con etanol (Merck, USA) al $60 \%$ por 24 horas. Luego, los microorganismos se centrifugaron por 10 minutos a $12.500 \mathrm{~g}$, se eliminó el sobrenadante y se incubó en una solución salina hipertónica $1 \mathrm{M} \mathrm{NaCl}, 0,1 \mathrm{M}$ de citrato de sodio y $0,5 \mathrm{mM}$ de EDTA (Sigma Chemical Co. USA) por 24 horas a $4{ }^{\circ} \mathrm{C}$. Posteriormente, los microorganismos fueron sonicados (Ultrasonic Homogenizer, serie 4710 Cole Parme USA) durante 20 minutos a 90 Watts, las células desintegradas se centrifugaron a $25.000 \mathrm{~g}$ por 30 minutos y el sobrenadante, que contenía las proteínas solubles, se dializó contra buffer fosfato salino (PBS). Posteriormente, las proteínas obtenidas se concentraron mediante el uso de Speed Vac SC 110 (Savant, USA) y fueron cuantificadas por el método Bradford, conservándose a $-20^{\circ} \mathrm{C}$ hasta su uso.

\section{ANÁLISIS ESTADÍSTICO}

Los valores obtenidos tanto en los conteos celulares del LBA como en las distintas pruebas a que fueron sometidos los animales fueron evaluados para determinar su normalidad mediante el test de Kolmogorov-Smirnov. Además, fueron comparados por el método Wilcoxon rank test, donde $\mathrm{P}<0,05$ fue considerado significativo.

\section{RESULTADOS Y DISCUSIÓN}

De los veintidós caballos Chilote del predio en que se realizó el estudio, trece mostraron síntomas compatibles con ORVA y nueve resultaron normales al examen clínico. Los animales positivos fueron a su vez agrupados en cuatro grupos de acuerdo a la severidad de su signología (cuadro 1); sólo un animal fue clasificado con ORVA de 8 puntos (signología clínica severa), que presentaba gran disnea, tos seca, secreción nasal abundante, ollares dilatados y miembros extendidos, producto de la dificultad respiratoria. El análisis de las células recobradas del LBA mostró en este ejemplar un $82 \%$ de neutrófilos. Los tres animales ORVA positivos que por sus signos clínicos fueron clasificados con 5-6 puntos (signología clínica moderada) mostraban una disnea importante, tos y secreción nasal evidente, y el examen citológico del LBA demostró un porcentaje de neutrófilos que variaron entre un $66 \%$ a $75 \%$. En el grupo con signología clínica leve (3-4 puntos), fueron incluidos cinco caballos ORVA positivos que mostraron disnea moderada con espiración abdominal y tos seca ocasional; el porcentaje de neutró-
Cuadro 1. Clasificación de los animales positivos y negativos a ORVA según su signología clínica (Robinson y col 2000), la edad de cada animal y el porcentaje relativo de neutrófilos presente en el LBA.

Clinical signology score according to Robinson et al (2000) in the horse population under study, showing the age of each animal and the relative percentage of neutrophils in the cells recovered from BALF (LBA).

\begin{tabular}{|c|c|c|}
\hline Signos clínicos de ORVA & $\begin{array}{l}\text { Edad } \\
\text { (años) }\end{array}$ & $\begin{array}{l}\text { Neutrófilos } \\
\text { en LBA (\%) }\end{array}$ \\
\hline Signos clínicos severos & 12 & 82 \\
\hline Signos clínicos moderados & $\begin{array}{r}2 \\
15 \\
5\end{array}$ & $\begin{array}{l}75 \\
66 \\
70\end{array}$ \\
\hline Signología leve & $\begin{array}{r}13 \\
2 \\
4 \\
5 \\
11\end{array}$ & $\begin{array}{l}58 \\
52 \\
46 \\
44 \\
40\end{array}$ \\
\hline $\begin{array}{l}\text { Signología clínica positiva } \\
\text { sólo después de ejercicios }\end{array}$ & $\begin{array}{l}3 \\
2 \\
3 \\
3\end{array}$ & $\begin{array}{l}33 \\
31 \\
20 \\
20\end{array}$ \\
\hline Ausencia de signos clínicos & $\begin{array}{r}10 \\
5 \\
11 \\
4 \\
4 \\
12 \\
7 \\
3 \\
6\end{array}$ & $\begin{array}{l}8 \\
6 \\
5 \\
4 \\
2 \\
2 \\
1 \\
0 \\
0\end{array}$ \\
\hline
\end{tabular}

filos en el LBA en este grupo varió en un rango de $40 \%$ a 58\%. Por último, en la clasificación 1-2, se incluyeron los cuatro animales positivos restantes que mostraban escasa signología clínica cuando estaban en reposo, en los cuales, hecho el examen citológico del LBA, se pudo observar un porcentaje de neutrófilos que varió entre un $20 \%$ y un $31 \%$. Los animales normales al examen clínico mostraron en las células recobradas del LBA un porcentaje igual o inferior al 8\% de neutrófilos, lo que está en perfecta coincidencia con lo reportado anteriormente (Hare y col 1994, Robinson y col 2001). De estos resultados parece evidente, en equinos con ORVA, la perfecta correlación que existe entre la presencia de neutrófilos en el árbol bronquial y los signos clínicos.

En la figura 1A puede verse el aspecto de un frotis de LBA normal en que abundan macrófagos, linfocitos y algunas células epiteliales, no observándose la presencia de neutrófilos. En la figura 1B se muestra un frotis del LBA que corresponde a un caballo con ORVA con signología clínica moderada en que se ve una gran cantidad de neutrófilos y una escasa presencia de macrófagos y linfocitos. 
Adicionalmente, como hallazgo curioso puede verse en la figura $1 \mathrm{C}$ el aspecto de un frotis de células obtenidas de un caballo positivo a esta enfermedad, mostrando un $57 \%$ de polimorfonucleares eosinófilos; observaciones como esta última han sido descritas anteriormente como consecuencia de parasitismo pulmonar, por lo general causado por Dictyocaulus arnfieldi o producto de la migración de áscaris, que preferentemente en el equino es Parascaris equorum (Morán y col 2006). También hallazgos similares han sido atribuidos a un cuadro poco frecuente en equinos denominado eosinofilia pulmonar idiopática (McGorum y Dixon 1994) o al efecto aditivo de las numerosas citoquinas producidas en los primeros estadios de una reacción de hipersensibilidad tipo I en el pulmón (Hare y col 1998). En este caso, esta última parece ser la causa del hallazgo descrito, ya que en lavados posteriores la eosinofilia fue reemplazada por una neutrofilia evidente; sin embargo, un efecto concomitante de una parasitosis para que se produzca esta eosinofilia exagerada no puede ser descartado ya que sabemos que los antígenos parasitarios son particularmente buenos inductores de células Thelper de tipo 2 (TH-2) cuya activación es necesaria para que se produzca la inflamación alérgica en el pulmón (Robinson 2001).

Otro hallazgo único en el grupo de animales estudiados lo constituye un caballo que presentó en el LBA un $86 \%$ de células epiteliales (figura 1D) cuando en general éstas no deben sobrepasar el 5\%, aumento que puede ser atribuido a causas iatrogénicas durante el lavado o a procesos infecciosos generalmente de carácter viral, siendo esto último la aparente causa de este hallazgo, ya que al examen endoscópico se pudo observar un gran daño de la vía aérea superior, con una exfoliación masiva del epitelio respiratorio. Además, una infección respiratoria viral previa de los equinos actuaría como un factor predisponente para desencadenar el cuadro de ORVA; lo más probable es que un animal afectado por un cuadro viral presente una respuesta mucho más severa a la inhalación de esporas de hongo, debido principalmente a la grave alteración producida por los virus sobre el sistema mucociliar, facilitando de esta manera la penetración de las esporas en el sistema respiratorio (Morán y col 2006); sin embargo, en este caso el equino no hizo ORVA ya que al evaluar posteriormente los fluidos bronquiales volvió a la normalidad en sus valores.

Al examinar el forraje de la población animal en estudio pudo determinarse la presencia de esporas de Aspergillus fumigatus en gran cantidad, hecho que no debe llamar la atención ya que Araya y Zaror (1995) demostraron la presencia de este hongo en un $80 \%$ de muestras de forrajes en 17 criaderos de caballos chilenos de las provincias de Valdivia y Osorno. Establecida la presencia de este hongo en el ambiente se quiso determinar el nivel de anticuerpos específicos presentes en el suero de estos animales contra antígenos de Aspergillus fumigatus. Los resultados demostraron, como puede verse en la figura 2, que tanto los animales ORVA positivos como los animales sanos mostra-

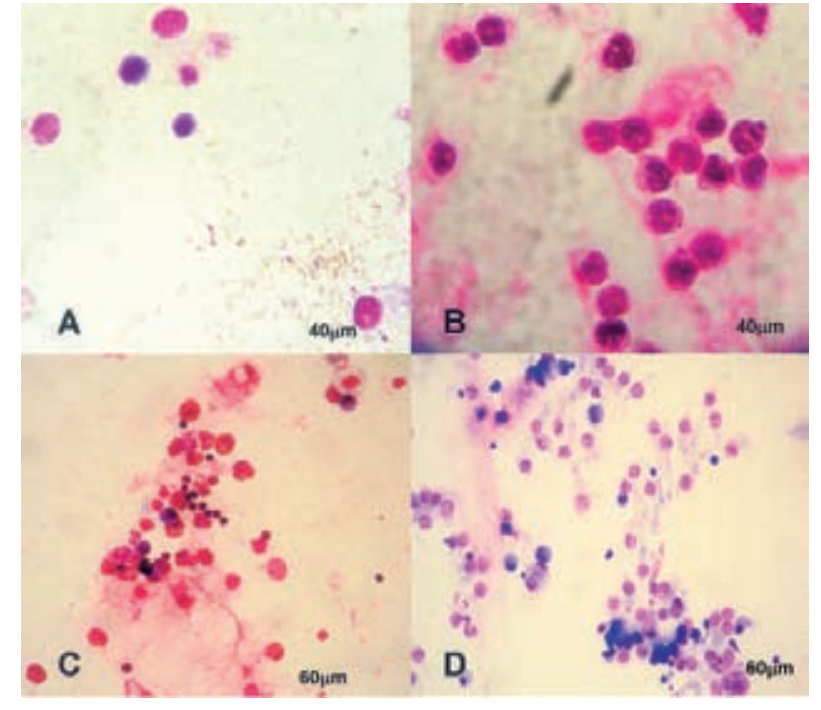

Figura 1. Citología de lavado bronquioalveolar de caballo Chilote: (A) citología caballo sano; (B) cuyo conteo diferencial indicó $80 \%$ de polimorfonucleares neutrófilos; (C) conteo diferencial de polimorfonucleares eosinófilos indicó 57\% y (D) conteo diferencial indicó un $86 \%$ de células epiteliales. Tinción May Grünwald-Giemsa.

Smears of cells obtained from bronchioalveolar lavage cytology of Chilote horse stained with May Grünwald-Giemsa. (A) Cytology obtained from a normal horse showing epithelial and mononuclear cells. (B) Aspect of a smear of an RAO positive horse showing great percentage of polimorphonuclear neutrophils. (C) Smear obtained in a special case were $57 \%$ of cells present in BALF were polimorphonuclear esosinophils and (D) a unique sample of BALF that shows $86 \%$ of cylindrical and ciliated epithelial cells.

ban niveles similares de inmunoglobulinas antiproteínas de Aspergillus fumigatus. Estos resultados concuerdan con lo descrito por Schmallenbach y col (1998) quienes sugieren que las proteínas de Aspergillus fumigatus son altamente inmunogénicas y además concuerdan con los reportes obtenidos por los mismos autores y Eder y col (2001), quienes encontraron que los niveles de IgG específica en el suero no tenían diferencia entre los caballos con ORVA y los individuos sanos. Sin embargo, estos mismos autores demostraron que los niveles de $\operatorname{IgG}$ e IgE específicas en el LBA eran significativamente más altos en individuos con ORVA que en caballos sanos. Estos resultados demuestran además la amplia distribución del antígeno, ya que todos los animales se encuentran inmunizados, dependiendo por tanto la presentación de la enfermedad a causas adicionales, probablemente localizadas en el árbol bronquial. Una de estas causas probables podría pertenecer al ámbito de la inmunidad innata, ya que está demostrado que los polisacáridos, glucanos, galactomananos y componentes proteicos de Aspergillus fumigatus en su primer encuentro con los fagocitos y el epitelio del árbol bronquial estimulan de inmediato a los TLR-2 y TLR-4, induciendo a estas células a producir citoquinas proinflamatorias IL-1 y TNFalfa (Meier y col 2003), lo cual induciría la secreción de IL-6 e IL-8, para seguir con la producción de IL-17 por 


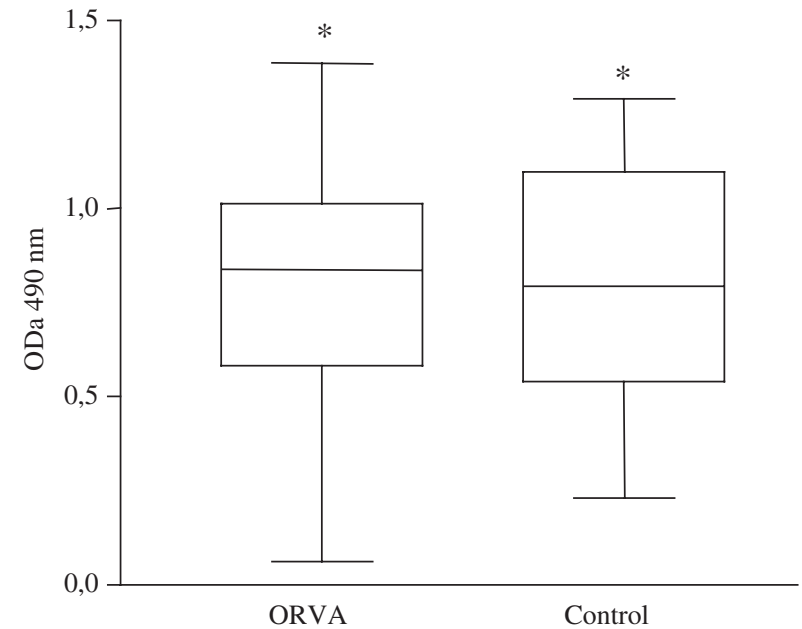

Figura 2. Niveles de inmunoglobulinas específicas para Aspergillus fumigatus en suero de caballos Chilote con ORVA y grupo control sano $(* \mathrm{P}>0,05)$.

Levels of specific antibodies against Aspergillus fumigatus in serum of RAO positive (ORVA) and control Chilote horses.

parte de células NKT residentes. IL-8 e IL-17 podrían explicar por sí solas la presencia de los neutrófilos en el árbol bronquial de los caballos positivos a ORVA, tal como parece estar demostrado en ratones y en asma humana (Afzali y col 2007); adicionalmente, este efecto podría verse reforzado con la formación de complejos inmunes que tienden a prolongar la inflamación pulmonar y a perpetuar la infiltración neutrofílica mediante la generación de factores quimiotácticos derivados de la activación del complemento. Esta mirada renovada de la patogénesis del ORVA viene, en cierta forma, a complicar la visión anterior más simplista que proponía una explicación basada en la superposición de una hipersensibilidad tipo I, mediada por anticuerpos reargínicos, con una hipersensibilidad tipo III mediada por complejos antígeno-anticuerpo.

Se puede concluir que los caballos Chilote, al igual que las otras razas equinas, tienen la predisposición de presentar ORVA al estar sensibilizados con los alérgenos inductores de este cuadro pulmonar, sugiriendo que la presentación de este cuadro alérgico pulmonar en equinos se debe a la interacción de factores genéticos y ambientales, al igual que los cuadros alérgicos humanos; además, los antígenos de Aspergillus fumigatus tienen un rol importante en la inducción de ORVA en esta raza de caballos.

\section{RESUMEN}

El objetivo de este estudio fue analizar las características citológicas del lavado bronquealveolar (LBA) y la respuesta inmune humoral en caballos Chilote con obstrucción recurrente de las vías aéreas (ORVA) contra Aspergillus fumigatus y su rol en la inducción de este cuadro alérgico. Para esto, se utilizaron 22 caballos Chilote, de los cuales 13 presentaban ORVA y 9 estaban clínicamente sanos, los cuales fueron utilizados como controles. A todos los animales se les realizó un examen físico, se les evaluó la citología pulmonar mediante un lavado bronqueoalveolar (LBA) y se les extrajo suero sanguíneo, con el propósito de determinar anticuerpos específicos contra Aspergillus fumigatus a través de un ELISA indirecto. Los resultados obtenidos de los extendidos celulares hechos a partir del LBA muestran que el porcentaje relativo de neutrófilos encontrados en los caballos con ORVA era concordante con los hallazgos obtenidos en el examen clínico. Con respecto a la prueba de ELISA se determinó que todos los animales, incluidos los controles, tenían niveles similares de anticuerpos específicos contra Aspergillus fumigatus no existiendo diferencias entre los individuos con ORVA y el grupo de animales sanos $(\mathrm{P}>0,05)$. Se puede concluir que los caballos Chilote, al igual que las otras razas de caballo, tienen la predisposición de hacer ORVA al estar sensibilizados con los alérgenos inductores de este cuadro alérgico pulmonar y que existe concordancia entre el porcentaje de neutrófilos encontrados en el LBA y la gravedad de los síntomas clínicos de estos animales. Además, los antígenos de Aspergillus fumigatus tienen un rol importante en la inducción de ORVA en esta específica raza de caballo.

\section{REFERENCIAS}

Afzali B, G Lombardi, RI Lechler, GM Lord. 2007. The roll of T helper 17 (Th17) and regulatory T cells (Treg) in human organ transplantation and autoimmune disease. Clin Exp Immunol 148, 32-46.

Araya O, L Zaror. 1995. Determinación de esporas de hongos y ácaros de vida libre en heno y paja en criaderos de caballos chilenos. Arch Med Vet 27, 41-45.

Barnes PJ, K Fan Chung, C Page. 1998. Inflammatory mediators of asthma: an Update. Pharmacol Rev 50, 515-596.

Cespedes S, E Andrews, H Folch, A Oñate. 2000. Identification and partial characterizations of a new protective antigen of Brucella abortus. J Med Microbiol 49, 165-70.

Clarke AG, T Madelin. 1987. Technique for assessing respiratory health hazards from hay and other source materials. Equine Vet $J$ $19,442-447$

Eder C, I Curik, G Brem, R Crameri, I Bodo, F Habe, S Lazary, J Solkner, E Marti. 2001. Influence of environmental and genetic factors on allergen-specific immunoglobulin-E levels in sera from Lipizzan horses. Equine Vet J 33, 714-20.

Escobar A, T Tadich. 2006. Caracterización biocinemática al paso guiado a la mano, del caballo fino Chilote. Arch Med Vet 38, 53-61.

Hare JE, L Viel, PM O'Byrne, PD Conlon. 1994. Effect of sodium cromoglycate on light racehorses with elevated metachromatic cell numbers on broncheoalveolar lavage and reduced exercise tolerance. $J$ Vet Pharmacol Ther 17, 237-244.

Hare JE, L Viel. 1998. Pulmonary eosinophilia associated with increased airway responsiveness in young racing horses. J Vet Int Med 12, $163-170$

Herszberg B, D Ramos-Barbon, M Tamaoka, JG Martin, JP Lavoie. 2006. Heaves, an asthma-like equine disease, involves airway smooth muscle remodeling. J Allergy Clin Immunol 118, 382-388.

Hockenjos P, Y Mumenoglu, H Gerber. 1981. Zur möglichen aetiologischen Bedeutung von Heumilben für allergisch bedingte Lungenkrakheiten des Pferdes. Schweiz Arch Tierheilk 123, 129-136.

Horohov DW, RE Beadle, S Mouch, SS Pourciau. 2005. Temporal regulation of cytokine mRNA expression in equine recurrent airway obstruction. Vet Immunol Immunopathol 108, 237-245.

Jackson CA, C Berney, AM Jefcoat, NE Robinson. 2000. Environment and prednisone interactions in the treatment of recurrent airway obstruction (heaves). Equine Vet J 32, 432-438.

Lavoie JP, K Maghni, M Desnoyers, R Taha, J Martin, Q Hamid. 2001. Neutrophilic airway inflammation in horses with heaves is characterized by a Th2-type cytokine profile. Am J Respir Crit Care Med 164, 1410-1413.

McGorum B, PM Dixon. 1994. The analysis and interpretation of equine bronchoalveolar lavage fluid (BALF) cytology. Equine Vet Educ 4, 203-209. 
McGorum B, J Ellison, R Cullen. 1998. Total and respirable dust endotoxin concentrations in three equine management systems. Equine Vet $J 30,430-434$.

Meier A, CJ Kirschning, T Nikolaus. 2003. Toll-like receptor (TLR) 2 and TLR4 are essential for Aspergillus-induced activation of murine macrophages. Cell Microbiol 5, 561-570.

Morán G, O Araya, H Folch. 2006. Obstrucción recurrente de las vías aéreas en el caballo. Arch Med Vet 38, 207-217.

Rementeria A, N Lopez-Molina, A Ludwig, AB Vivanco, J Bikandi, J Ponton, J Garaizar. 2005. Genes and molecules envolved in Aspergillus fumigatus virulence. Rev Iberoam Micol 22, 1-23.
Robinson NE, MA Olszewski, D Boehler. 2000 Relationship between clinical signs and lung function in horses with recurrent airway obstruction (heaves) during a bronchodilator trial. Equine Vet $J$ 32, 393-400.

Robinson NE. 2001. International workshop on equine chronic airway disease, Michigan State University. Equine Vet J 33, 5-19.

Schmallenbach KH, I Rahman, HH Sasse, PM Dixon, RE Halliwell, BC McGorum, HR Miller. 1998. Studies on pulmonary and systemic Aspergillus fumigatus-specific $\mathrm{IgE}$ and $\mathrm{IgG}$ antibodies in horses affected with chronic obstructive pulmonary disease (COPD). Vet Immun Immunopathol 66, 245-256. 